\title{
Can robots possess knowledge? Rethinking the DIK(W) pyramid through the lens of employees of an automotive factory
}

\author{
Johanna Hautala (1) 1,2凶
}

Knowledge, information, and data are increasingly processed in human-robot collaboration. This study tackles two requirements for revising the concepts of knowledge, information, and data. First is developing robots' knowledge capabilities and transparency and ensuring effective division of tasks between humans and robots to increase the productivity of robotised factories. Employees' interpretations of robots' abilities to possess knowledge reveal their assumptions of robots' possibilities and limitations to create knowledge-based products with humans. Second, the classic DIK(W) pyramid of data, information, knowledge, and wisdom is a theoretical construct requiring additional empirical research. This empirical exploratory study develops the DIK(W) further and applies it as a tool to understand employees' perspectives of robots and knowledge. Do people believe robots possess knowledge? What kind of knowledge can (or cannot) robots possess? A survey $(n=269)$ was collected from the most robotised factory in Finland, Valmet Automotive. Half of the respondents think robots can possess knowledge, but only with humans. These respondents were more likely to trust robots compared to those who think robots cannot possess knowledge. As the key contribution, the DIK(W) pyramid is reconceived by (i) acknowledging robots and humans, (ii) turning the pyramid upside down, and (iii) recognising knowledge as a dividing concept.

\footnotetext{
${ }^{1}$ University of Vaasa, Vaasa, Finland. ${ }^{2}$ University of Turku, Turku, Finland. ${ }^{凶}$ email: johanna.hautala@uwasa.fi
} 


\section{Introduction}

oday, work across the world and across industrial fields is being robotised because robots are becoming increasingly independent and capable of performing demanding tasks alongside people (Bauer, 2017; Bissell and Del Casino, 2017). The production in robotised factories connects people and robots into a co-creation process, where data and information are collected, analysed, and transformed into a justified, novel, valuable, and trustworthy knowledge that is required to build high-quality products such as cars (Anthes, 2017). Developing robots that are more independent and collaborative in factories requires attention to the robots' cognitive abilities to process and utilise data, information, and knowledge (Lobov, 2018; Mishra, 2018; Hentout et al., 2019; Yao, 2020). However, data, information and knowledge are concepts that originate from people, who are significantly different from robots. Robots lack emotions and consciousness. Yet, people who work with robots may still trust them and see them as team members (Pohlt et al., 2018; Campanozzi et al., 2019; Larson and DeChurch, 2020; Panganiban et al., 2020; Matthews et al., 2020).

There is a practical and scientific need to revise the concepts of knowledge, information and data from the perspective of employees who work with robots. In general, the topic of knowledge is lacking in robot-related research (Jerman et al., 2020; Elprama et al., 2016). Practical needs concern the robotised factories and developing cognitive robots. Increasing the productivity in a factory is possible by enhancing robots' knowledge capabilities and transparency as well as ensuring effective division of tasks between humans and robots (Lee and Moray, 1992; Milliez et al., 2016; Hentout et al., 2019; Matthews et al., 2020). The better robots can process data, information, and knowledge, the more complex tasks they can execute in factories. People can understand transparent robots' functions, decisions, and information processing. From the perspective of a factory, transparency is crucial: To divide tasks between people and robots and create high-quality products, employees need to recognise robots' faults, limitations, and possibilities in the knowledge-based production process (Kahan et al., 2009). In relation to robots, knowledge is a dividing concept-some scholars think robots can possess knowledge (Das et al., 2007; Luo et al., 2015; Miao et al., 2018) and others think they cannot (Sanzogni et al., 2017; Sardar, 2020; Picca, 2020). Thus, challenging the employees of a robotised factory to form their justified opinion about robots' ability to possess knowledge will reveal their assumptions of robots' abilities and limitations to create knowledgebased products with humans.

The scientific motivation of this article concerns the classic DIK(W) pyramid (Ackoff, 1989), where co-creation includes transforming data (D) into information (I), knowledge (K), and wisdom (W). The DIK(W) is a fundamental model for academic knowledge-related disciplines, such as information science, computer science, and knowledge management (Rowley, 2007; Yao, 2020). In this article, the DIK(W) is a tool to investigate the perspectives of the employees of an automotive factory regarding robots' ability to possess knowledge. Reconsidering knowledge is specifically relevant in the wider context of robotising a knowledgebased economy, where knowledge is increasingly ascribed to machines, which may change the current human-centered understanding of knowledge (Rowley, 2007; Sanzogni et al., 2017; Sardar, 2020). Furthermore, the article further develops the DIK(W), which has been criticised for lacking empirical analysis and not recognising tacit knowledge or knowledge emerging outside of empirical and measurable data (Frické, 2009, 2019).

This exploratory study aims to rethink the DIK(W) pyramid through the lens of human-robot co-creation from the perspectives of employees working on various tasks in a robotised factory. A survey ( $n=269$ ) was conducted in 2019 with employees from the most robotised factory in Finland, Valmet Automotive. In this factory in the small city of Uusikaupunki, more than 1.5 million vehicles have been manufactured. The aim of Valmet Automotive is to produce high-quality, trustworthy, and safe cars (Valmet Automotive, 2020). The questions explored here are as follow: (i) Do the employees believe robots possess knowledge? (ii) What kind of knowledge do the employees believe the robots can or cannot possess? (iii) Are the employees who believe robots possess knowledge more likely to trust them and view them as teammates compared to employees who do not consider robots able to possess knowledge? The survey was analysed with content analysis, cross-tabulations, and the $\chi^{2}$ test.

The article has three key sections. First, after identifying the gap in the topic of knowledge concerning robot-related research, the previous research applying the DIK(W) pyramid is reviewed. This review specifies the ways in which the categories of data, information, and knowledge are currently defined. Second, the survey results are analysed in close reflection with the previous understandings of the DIK(W) pyramid. Third, based on the results and previous research, the DIK(W) pyramid is developed and adjusted to the human-robot co-creation process.

According to the key results, 54\% of employees believe robots possess knowledge, but most of them mentioned this is possible only with humans. These respondents trust robots statistically more often than the $46 \%$ who think robots do not possess knowledge. Employees who believe robots cannot possess the knowledge to relate this ability to a particular kind of actor that is independent and can use knowledge in justified, novel, and creative ways, as well as in changing situations. As the key contribution of this paper, the $\mathrm{DIK}(\mathrm{W})$ pyramid is rethought in three ways: first, by acknowledging differences in robots and people as knowledge-related actors; second, by turning the pyramid upside down and reorganising the relations of data, information, and knowledge; and third, by recognising knowledge as a concept that divides employees via the independency of the actor who can possess knowledge.

\section{Robot-related research tackles knowledge indirectly}

Research specifically on attitudes towards robots that have been conducted within the past 10 years offers important findings for this article (Ray and Mondada, 2008; Rantanen et al., 2018; Campanozzi et al., 2019; MCBride et al., 2019; Matthews et al., 2020; Biswas et al., 2020). The next review helps with identifying two important gaps. First, empirical research has covered topics related to knowledge only indirectly. Very few researchers have attempted to find out whether people working with robots believe they possess knowledge, and likewise, little research has explored the kinds of knowledge involved. Second, current research is focused on a rather limited set of sectors, especially the healthcare (e.g., Rantanen et al., 2018; MCBride et al., 2019) and military (e.g., Matthews et al., 2020) sectors. Even though automotive factories are among the most robotised workplaces in the world (International Federation of Robotics, 2017), very few studies have surveyed the general views of their employees (excluding Matthias et al., 2011; Hippertt et al., 2019).

An important topic covered by current research concerns teams (i.e., basic units of interactive knowledge creation). Recently, researchers have started to investigate whether people working with robots consider them team members or peers. Empirical studies have confirmed this notion (e.g., Pohlt et al., 2018; Larson and DeChurch, 2020; Panganiban et al., 2020). This is due to the ability of robots to "receive information" as well as "process and plan, and interact" with people (Panganiban et al., 2020, p. 1); in other words, 
perform knowledge-related tasks. A robot as a team member fulfils "a distinct role that directly contributes to team performance" (Matthews et al., 2020, p. 4). In theory, this would be the case in a robotised automotive factory. The manufacturing process of new cars in the Valmet Automotive (2020) in Finland has been organised according to human-robot collaboration. The process is divided into sequences operated by robots and people. In fact, cars would be very difficult to build in a factory without robots. However, in practice, some employees may see robots as team members, whereas others might not.

To work on human-robot teams, people need to trust a robot will fulfil its role in the process of co-creating high-quality, safe cars. Trusted robots become actors: They are "'more' than mere tools" (Coeckelbergh, 2012, p. 57). From an instrumental perspective, people may trust robots directly "to do what it is meant to do as an instrument to attain goals set by humans," or indirectly by trusting the person who designed and uses the robot (Coeckelbergh, 2012, p. 54). Deeper psychological forms of trust can also develop. Humans create beliefs about robots, and based on these beliefs, they decide to trust a robot in particular interactions (Taddeo, 2010, p. 244). People may consider robots actors and social beings similar to animals, which creates a social relationship in which people default to trusting them (Coeckelbergh, 2012, p. 58).

Research has found that trust in robots depends on situations. For example, young people are willing to trust robots in tasks such as cleaning and driving a taxi, but they are less willing to trust robots to provide safety, care for elderly people, or teach (Campanozzi et al., 2019, p. 49). People learn to trust machines gradually (Lee and Moray, 1992) and can rebuild their trust in robots that have failed to perform as expected (Pynadath et al., 2019). The connection between trust and knowledge implicitly exists: Trust has been found to increase people's perceptions of robots as "transparent" (Lee and Moray, 1992; Matthews et al., 2020). Transparency means people understand the robots' decision-making processes. Experts in robotics and engineering have sufficient knowledge to form accurate mental models of robots' activities (Matthews et al., 2020 , p. 3), which suggests they can see robots as transparent and trust them more easily than non-experts can.

\section{Data, information, and knowledge-the DIKW pyramid}

The DIKW model is visualised as a pyramid (Fig. 1). This model describes the quantity, hierarchy, and process from the bottom (data) to the top (wisdom). A large amount of data and information are needed to build a foundation that supports smaller pieces of knowledge and wisdom at the top. In other words, we need cognitive machines that can handle big data to create a little knowledge (e.g., Batra, 2014; Jifa and Lingling, 2014). The compression of data and information is sometimes visualised as a funnel-a pyramid upside-down (Fig. 1) (Rowley, 2007, p. 177).

Data consist of "symbols that [...] are products of observation and $[\ldots]$ that represent the properties of objects, events and their environment" (Ackoff, 1989, cited in Rowley, 2007, p. 166). Data are adequate with respect to a conceptual model of reference. When observations are not adequate, they should be corrected (Frické, 2009). Applying real-time big data in analyses risks including observations that are not adequate, which means inadequate data will be increasingly used in knowledge creation processes (Sardar, 2020). Data have no meaning because a datum "resides outside of the human mind" (Baskarada and Koronios, 2013, p. 13). Thus, data are accessible to machines. For example, robots collect data with sensors (e.g., temperature and location; Ardolino et al., 2018).

The next three pieces of the pyramid are more difficult to define (Rowley, 2007). Originally, information was defined as descriptions of the data that "answer to questions [...] who, what, when, and how many" (Ackoff, 1989, cited in Rowley, 2007, p. 166). According to

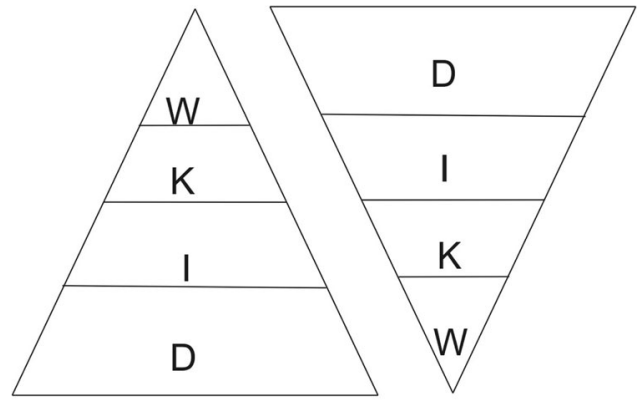

$$
\begin{array}{ll}
W=\text { wisdom } & \text { I = inform } \\
K=\text { knowledge } & D=\text { data }
\end{array}
$$

Fig. 1 The DIKW model. Two basic visualisations: pyramid (left) and funnel (right). $\mathrm{D}=$ Data, $\mathrm{I}=$ Information, $\mathrm{K}=$ Knowledge, $\mathrm{W}=$ Wisdom

Frické (2009), information should also include the question "why?" In terms of this study, the key debate in defining information concerns meaning. Some scholars conclude information bears meaning, but some conclude that meaning is added only when information is interpreted as knowledge. In this article, information and knowledge are considered according to the latter option. Information is "signs bearing data" (Picca, 2020, p. 34). Information can be completely controlled and formalised via codification methods (e.g., text, a coded programme, or a mathematical model; Nonaka and Takeuchi, 1995). For example, the $p$ value of 0.001 is a sign: It is a result of a statistical analysis of a data set. However, it does not bear meaning until a person interprets the sign (e.g., attaches meaning to it). The $p$ value may verify a hypothesis and bring new knowledge to a research field. If information is defined in this way (without meaning), then it is accessible for machines. For example, the robot's activity is determined by its software and algorithms that define the type of data the robot collects and the way it processes the data (e.g., applies location data to move; Ardolino et al., 2018).

In general, DIKW applications describe knowledge from a human-centric view with terms such as "learning," "understanding," "expert views," and "perception" (Rowley, 2007, p. 172). According to Rowley (2007, p. 166), Ackoff (1989) defined knowledge as knowhow that enables "transformation of information into instructions" (Ackoff, 1989, cited in Rowley, 2007, p. 166). The ability to interpret (make information meaningful) is crucial for creating knowledge, such as outcomes that are justified, trustworthy, new, and valuable. Understood in this way, knowledge is not a separable category of a pyramid but rather a process and activity. Moreover, it is more than what Ackoff (1989) suggests: formulating explicit instructions (algorithms) from data and information. In this article, knowledge cannot be separated from wisdom, which according to Ackoff (1989, cited in Rowley, 2007, p. 166) is the "ability to increase effectiveness" and add value via judgement, ethics, and aesthetics. Therefore, the model is referred to in this article as $\operatorname{DIK}(\mathrm{W})$ : data, information, and knowledge (wisdom).

Knowledge is interestingly connected to creativity and repetition. On the one hand, knowledge should be repeatable or otherwise, it can be contested: repetition demonstrates the difference between success and failure (Green, 2012, p. 107). Repetition requires complete data and information (Hogarth, 2001). In technology and manufacturing, routines and repetition are embodied in standardisation that is designed for guaranteeing high-quality production (Shalley and Gilson, 2017, p. 609). Thus, repetition offers a stable structure required to generate new knowledge (Slutskaya, 2006, p. 151). Robots include software (programmes) that enable their tireless, accurate, and rigid repetition, and thus a stable structure for new knowledge. 
On the other hand, knowledge is often defined as "new," which connects knowledge with creativity, freedom, and intuition (Picca 2020). Creativity is the generation of original (new) and effective ideas or products (Pereira, 2007; Runco and Jaeger, 2012). Creating something new often requires intuition, which means making decisions based on combining incomplete data and information with feelings (Hogarth, 2001). However, creativity and intuition are also connected with repetition. For example, creativity can also help in effectively managing "routine tasks required to make commodity products" (Shalley and Gilson, 2017, p. 605), while intuition requires learning from experience (Epstein, 2010, p. 299). For the individual, the creative process is an enjoyable experience of flow, where time feels as though it disappears as a person challenges his or her high-level skills to make a discovery (Csikszentmihalyi, 1997).

Frické (2009, pp. 133-134) brings out an important notion about the pyramid: It is assumed that all knowledge and wisdom are based on data, but only explicit and measurable observations can be turned into data. Thus, the pyramid can describe only knowledge that is created from explicit data that can be coded into text and models (Nonaka and Takeuchi, 1995). This relates to a positivist tradition and a rational approach to knowledge, which is common for engineers who consider machines able to possess knowledge (Forsythe, 1993). For example, proponents of the rationalist approach cannot recognise its tacit and embodied dimensions (Frické 2009; Hautala and Höyssä, 2017). Our knowledge is based on tacit knowledge that we cannot express directly (Polanyi, 1983). Such tacit knowledge is embodied in communities, interactions, and individual behaviour, and it is very important for any knowledge creation process (Collins, 2010).

From the perspective of robotics, knowledge is a dividing concept. Some researchers state that the "robot knows". For example, a robot might know its position, the environment, its velocity, and the states of other objects, as well as understand human messages, or it might possess a knowledge base that it uses to communicate with humans (Das et al., 2007; Luo et al., 2015; Miao et al., 2018). Other researchers have stated that based on the human-centric perspective of knowledge, even the most developed robots are not yet conscious beings (Lake et al., 2017) and thus cannot "know." The research review demonstrated that robots might be able to possess knowledge if knowledge is defined from the rational and positivist approach. However, if knowledge is considered connected with the tacit and embodied dimension, creativity, and intuition, then robots are limited in possessing knowledge because they lack feelings, embodied experiences, and awareness of self and meaning (Sanzogni et al., 2017; Sardar, 2020; Picca, 2020). In this article, both tacit and explicit elements co-constitute knowledge (Sanzogni et al., 2017, p. 38).

DIKW in robot engineering. The DIKW pyramid is applied to developing robots that could possess the knowledge and create knowledge with people. Mishra (2018, p. 285) suggested the DIKW model is an "architecture for cognitive engineering". The benefit of this model is its clear structure (data, information, knowledge, and wisdom), which is possible to code-at least to some extent. According to Lobov (2018), the pyramid allows for the "division of a problem into subproblems and solving those in turn, focusing on each [...] separately".

The key challenge is to build the hierarchy (e.g., to connect data to information, information to knowledge, and knowledge to wisdom). In general, and beyond engineering science, this transformation is not understood well (Rowley, 2007, p. 168). It is often mixed with the geographical dimension of a transfer (Heino and Hautala, 2020). Data and information can be transferred "as is," or unchanged, from one actor to another-and between people and machines
(Panganiban et al., 2020, p. 2). Despite this, robots can process information rapidly and transfer altered information to humans (Panganiban et al., 2020, p. 2). In general, interpretation is required to transform information into knowledge. Along these lines, knowledge (as interpreted and meaningful) cannot be transferred (unchanged) because each time it moves, it is reinterpreted, and thus, knowledge changes (Heino and Hautala, 2020).

In robotics, transparency is an important term behind the transformation. Transparency allows humans to understand a robot's functions (Matthews et al., 2020). It is the ability of the robot "to effectively communicate information to the human in order to enable an accurate understanding of the agent's current goals, reasoning, and future states" (Guznov et al., 2020, p. 2). Therefore, transparency allows for trust in robots (Matthews et al., 2020; Guznov et al., 2020).

Yao (2020) and Mishra (2018) answer the challenge of transformation via the activities of a robot. In Yao's (2020) application, information equals knowledge. The robot needs to

1. Collect (data)

2. Analyse (transform data into information and knowledge)

3. Make a decision (based on information and knowledge, i.e., wisdom).

Thus, for Yao (2020), a robot can possess wisdom, but for Mishra (2018), robots can only possess data, information, and knowledge. Mishra (2018, p. 287) identifies the transformations of the DIKW pyramid in both ways; for example, from data to information, and from information to data. Robots can conduct some transformations independently (in Steps 1,5-6, below), and some with people (Steps 2-4). The steps are as follows (Mishra, 2018, p. 288):

1. Analyse: A robot organises (labels) data. Data are transformed into information.

2. Synthesise: A robot connects labels together, but this activity requires human help for a few more years. Information is transformed into knowledge.

3. Be intuitive and apply emotions. It will take at least a decade to develop machines with such skills. Knowledge is transformed into wisdom.

4. Plan and desire: It will take at least a decade to develop machines with such skills. Wisdom is transformed into knowledge.

5. Break the plan into executable steps (i.e., commands): Knowledge is transformed into information.

6. Break the steps into executable signals "that can be understood by the actuators" (e.g. "hands" of the robot). Information is transformed into data.

Survey in the Valmet Automotive Factory in Finland. According to Valmet Automotive (2020), the company was founded in 1968 and today it is the only manufacturer of cars in Finland. Moreover, it is the most robotised factory of Finland, according to the firm. The factory is located in Uusikaupunki, a city of about 16,000 inhabitants along the coast of the Baltic Sea in Southwest Finland. Valmet Automotive focuses on producing expensive, high-quality cars and was awarded the most valuable collaboration partner of Mercedes-Benz in 2016. The company is organised into various sections. The manufacturing process, where the robots are located, includes the following subdepartments: body shop, paint shop, general assembly, testing, and finishing. In the background of the manufacturing process exists the subdepartments of logistics, research and development, financial administration, and human resources.

In general, Finland is a technologically advanced country and was one of the first countries to launch a strategy to enter the era of artificial intelligence ("Finland's Age of Artificial Intelligence," 2017). 
Table 1 Arguments were proposed in the following order.

\section{Answer the following arguments concerning the Valmet Automotive}

(1) Today, high-quality cars cannot be produced without robots

(2) I like to work with robots

(3) I can build a car without robots

(4) I trust the robots of the factory

(5) Humans make mistakes more often than robots in the factory do

(6) In the future, the ability to work with robots is a necessary skill

Answers were analysed through three categories: I disagree, I neither disagree nor agree, and I agree.

\begin{tabular}{|llr|}
\hline Table 2 Survey respondents. & & \\
Variables & Groups & $\boldsymbol{n}(\%)$ \\
\hline Gender $(n=269)$ & Male & $167(60)$ \\
& Female & $102(40)$ \\
Age (years; $n=269)$ & $19-25$ & $44(16)$ \\
& $26-35$ & $88(33)$ \\
& $36-45$ & $55(20)$ \\
& $46-55$ & $64(24)$ \\
Years worked at Valmet Automotive & $56-65$ & $18(7)$ \\
( $n=269)$ & $0-1$ & $36(13)$ \\
& $2-6$ & $160(60)$ \\
Years worked in a section $(n=257)$ & over 6 & $73(27)$ \\
& Manufacturing & $185(72)$ \\
& Other & $72(28)$ \\
\hline
\end{tabular}

In this strategy, Finland aimed to become a global leader in applying robotics and artificial intelligence widely in society, particularly in industry. To place Finland within the wider context of European robotics, it is compared to Germany. Germany is Europe's leading country with a strong automotive industry and has 309 robots per 10,000 industry employees. Globally, Germany ranks third, whereas Finland ranks 16th with 138 industrial robots per 10,000 industry employees (International Federation of Robotics, 2017). Finland's context is similar to those of many other non-leading countries and industries worldwide whose strategic aims are to work increasingly with robots.

The survey method was selected for collecting empirical material because it allows obtaining the general perspectives of the employees of a robotised workplace. The survey included seven questions concerning robots: the task of the respondent (Questions 1-3), understanding of team (humans; humans and robots; other; Question 4), set of arguments (Question 5; Table 1), and skills and knowledge (Questions 6 and 7). Existing research concerning trust and teams, as well as results of a substudy of the same research project, was applied in the construction of the arguments. In general, arguments are a useful method to collect opinions with a survey (Eyvindson et al., 2015). However, because respondents tend to agree with the arguments (Schuman and Presser, 1996), the core questions of the survey regarding knowledge were not included as arguments.

Electronic survey results were collected in May 2019. The survey is part of the project "Second Machine Age Knowledge Co-Creation in Space and Time" (2018-2023, funded by the Academy of Finland) that has been approved by the University of Turku Ethics Committee. The survey respondents were able to read the privacy notice and gave their consent. At the time, the factory included about 4500 employees (Valmet Automotive, 2020). The survey, along with one reminder, was sent to the e-mail list and Facebook group of the Valmet
Automotive staff. A total of 269 respondents completed the section of the survey reported in this article, which means the response rate was low $(6 \%)$. This limits the possibility of generalising the results of the article. Along these lines, I do not state that the attitudes of the respondents towards robots apply to the whole factory. I consider the low response rate specifically when answering Research Question 3. However, the survey is conducted with good scientific quality, and the survey is valuable and relevant for publishing the results for two reasons. First, this exploratory study concentrates on an issue that has seldom been studied empirically (see Introduction). Second, the focus of this article is on understanding the reactions of the employees towards robots as knowledgeable beings. A total of 251 responses to the question "In your opinion, can robots possess knowledge? If yes, what kind of knowledge? If no, why not?" generate a very interesting basis for rethinking the DIK(W) pyramid. Table 2 shows the basic information of the respondents.

The survey was analysed with statistical and qualitative methods. IBM SPSS software for statistical analysis was applied to answer Research Questions 1 and 3. Frequencies were enough to answer Question 1. Crosstabs and the related $\chi^{2}$ test were applied to answer Question 3. The $\chi^{2}$ test is suitable for recognising differences between groups; for example, whether a difference exists between Group A (those who think robots can possess knowledge) and Group B (those who think robots cannot possess knowledge) in their answers to other questions (e.g., whether they agree with "I trust robots"). The $p$ values of the $\chi^{2}$ test were considered to be very significant $(p \leq 0.001)$, significant $(0.001<p \leq 0.01)$, or almost significant $(0.01<p \leq 0.05)$.

The second research question was answered with data-driven conventional content analysis (Hsieh and Shannon, 2005). In the survey, the respondents were asked to explain in their own words the kinds of knowledge robots can possess or the reasons robots cannot possess knowledge. After the first round of analysis, the actor (not mentioned, robot, human, or robot and human) was recognised as the key factor by which to group the explanations. Thus, groups were accordingly formed. Through a visual presentation and key quotes, the results were analysed in the light of the DIK(W) model.

\section{Results}

Can robots possess knowledge? The 251 answers to the question "Can robots possess knowledge?" are divided: about 54\% $(n=135)$ say yes and about $46 \%(n=116)$ say no. The respondents who believe robots possess knowledge include men and women, are in all age groups, work in all subdepartments of the factory, work more directly with robots or apart from the robots, and are more and less experienced with working at Valmet Automotive. No statistically significant differences exist among these groups. However, a difference is identified $(p=0.017)$ between experts and workers: The experts $(60 \%)$ thought robots 


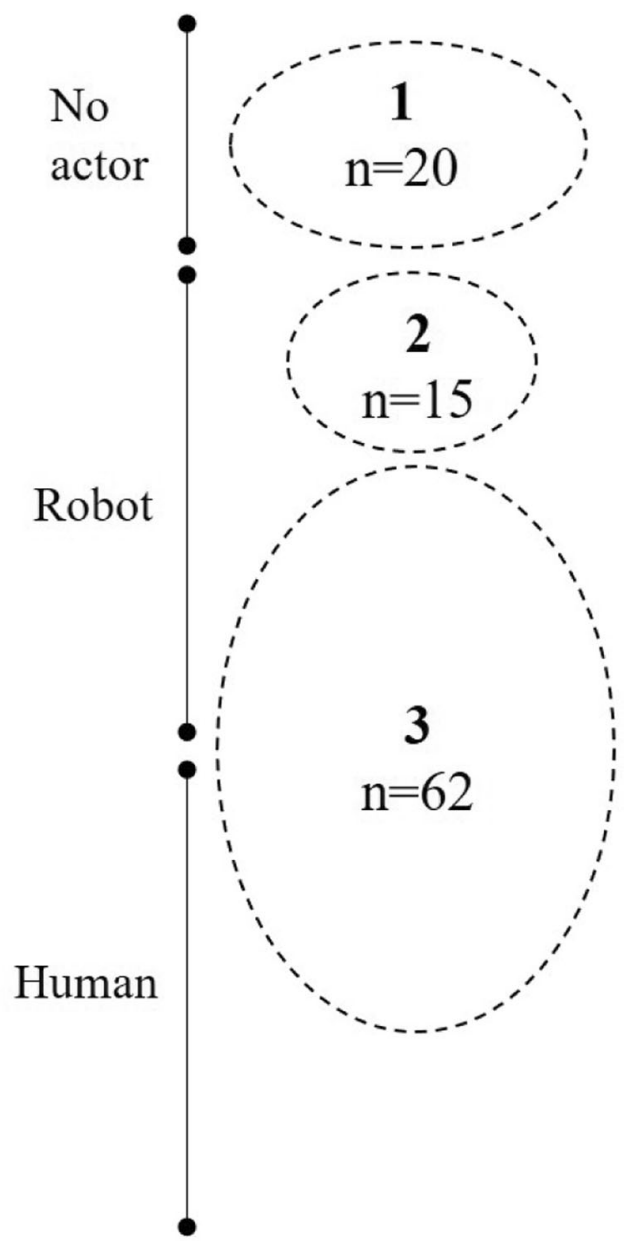

Fig. 2 What kind of categories of knowledge can robots possess?

Answers form three categories based on the actor possessing knowledge (no actor, robot, or robot and human together). $1=$ Data, $2=$ Information, $3=$ Knowledge.

possess knowledge more often than workers (52\%) did. The 130 experts especially include people with the job titles of leaders (55 persons, $42 \%$ ), engineers (32 persons, $25 \%$ ), and designers (14 persons, $11 \%)$. The job titles of 97 workers are more versatile and include, for example, 23 mechanics (24\%), 16 measurers of quality (16\%), 10 substitutes (10\%), and seven repairers $(7 \%)$.

What kind of knowledge can robots possess or not possess? Thus, an in-depth analysis is required to understand what the respondents mean by "knowledge." An explanation of the question "Can robots possess knowledge?" was requested in a respondent's own words after either the "If yes, then what kind of knowledge?" or "If no, then why not?" prompts. Altogether, 149 respondents provided useful explanations (excluding, e.g., "I do not know"). The useful descriptions of knowledge robots can possess $(n=95)$ form three categories, which differ in terms of the activity and actor: not mentioned, robot, or robot and human together (Fig. 2).

In the first category, knowledge was described without connection to any actor $(n=20)$; for example "10101010," "codes," "parameters," "location data," and "documents and logs". Considered via the DIK(W) model, these examples represent data: explicit and codified data sets related to positions of robots, documents, logs, and error reports. Some robots can collect data via their sensors (Ardolino et al., 2018; Yao, 2020), but other data, such as software code, require human activity although it is not mentioned.

The second category $(n=15)$ consists of examples of robot's activity without mentioning the human:

- Memory that traces their activities

- Robot is a pile of sensors that observe the robot

- Knowledge of what it is supposed to do at a particular point

- Knowledge of locations that enables them to move exactly as they are supposed to

- (Ability to) work in their own areas without colliding

- Expressing errors and observing deficiencies

These examples can be formalised and controlled with methods of codification (Nonaka and Takeuchi, 1995). This category resembles information or "signs bearing data" (Picca, 2020 , p. 34); that is, data that are applied in commands (signs) telling the robot to move (see also Mishra, 2018, for this interpretation of robot's information). With the underlying assumption that information is related to human actors, Ackoff (1989; cited in Rowley, 2007, p. 166) and Fricke (2009) suggested information should answer questions relating to who, what, when, how many, and why. This list of questions needs revising because when information is related to a robot actor, "where" is necessary, but "why" can be questioned. Location is critical information for a robot to move (its actuators) and deliver its tasks (Rusu et al., 2009; Cruz et al., 2019). However, answering "why" is difficult for a robot. As one respondent stated, "Robots possess knowledge mainly about their own task, not about the production more widely". Understanding the production process-the "why" of each robot's activity-belongs to the people in Valmet Automotive.

In the examples of the third category $(n=62)$, robot activities that require people (i.e., an operator) are presented.

- They are programmed, so they possess knowledge of what they should do.

- Programmable knowledge, but the robot does not recognise without limit values (whether something is) ok or nok (not ok). Programming is the key adding "knowledge".

- A simple robot does not possess (knowledge), but it possesses programmed memory (software) that enables it to move as we want it to.

- "Knowledge" is needed to fill the commands of the operator.

In the $\mathrm{DIK}(\mathrm{W})$ model, knowledge is human-centered (Rowley, 2007) and connected to praxis (Picca, 2020). The most common expressions in this category involve humans "programming" robots $(n=38)$. This creates a hierarchical relationship between humans and robots: the programmer (creates) and the programmed (executes), which transforms human knowledge into robot information. People connect robots to their praxis and the production process of the factory. Thus, robots cannot possess all dimensions of knowledge without people-specifically the dimensions that are tacit and related to the overall production process.

Of those who considered robots to be unable to possess knowledge $(n=116), 98$ justified why they believed this. Experts provided these explanations more often than workers did $(p=0.042)$. Nevertheless, it is very interesting to understand what employees working with robots think about the limitations of robots and the abilities of people in the knowledge co-creation process. Half (49\%) of the justifications are related to the humancentric view of knowledge (Rowley, 2007; Picca, 2020). 
The shortest justifications sum it up: "Robot is not a human" and "expert has the knowledge". Longer justifications reveal three more detailed lines of argumentation. The first draws attention to the human-robot hierarchical relation, where humans control the robots, humans use programming as the medium of control, and robots are only tools-unable to perform a "free act" (Picca, 2020, p. 35). Although programming transfers explicit elements of human knowledge to a robot, something crucial in knowledge is lost during the transfer, which is why it can no longer be considered "knowledge":

- There is only knowledge that humans have programmed.

- They are only machines that have been programmed with our know-how.

- A robot is only a tool that does exactly as it is programmed to do.

- They are machines programmed by humans. Humans possess knowledge.

The second line of argumentation draws attention to the novelty and process aspects of knowledge. The respondents connect activity, applicability, and reactivity to knowledge. For the respondents, to possess knowledge means to use it in justified, novel, and creative ways in changing situations. Although robots are best in accurate and tireless repetition, the respondents contest the connection between repetition and knowledge (Slutskaya, 2006; Shalley and Gilson, 2017). Instead, they connect knowledge with creativity, which requires emotions and the ability to experience and understand social relations and specific contexts of fields, organisations, and cultures, which current robots lack (Csikszentmihalyi, 1997; Epstein, 2010; Green, 2012; Mishra, 2018).

- Human feeds the code to robots, and robots only repeat it.

- Taught "blind" repetitions.

- Robot is only a machine that repeats its programme.

- Everything is just transferred to the robot; it does not learn anything.

- Robot is a machine that does what it has been programmed to do. One can save knowledge to the robot's memory, but the robot cannot use that knowledge in a creative way.

- They just repeat; they do not develop anything new.
- Robots possess only the programmed parameters and cannot apply these in problematic situations.

- Robots only follow programmed instructions and report what they are told to report; they do not possess or generate knowledge.

The third line of argumentation draws attention to selfawareness and the processes of cognition, which are human traits, not yet robot features. "Robots act according to how they are programmed to act and use the data collected through their sensors. Robots 'possess knowledge,' but they do not 'think independently". Thus, even if a robot makes "just a small mistake, the robot cannot understand it" or "know it," which may lead to problems for the factory. This argumentation supports the notions that machines cannot access knowledge because it is tacit and embodied (Sanzogni et al., 2017; Sardar, 2020; Picca, 2020).

Are those who believe robots possess knowledge more likely to trust robots and consider robots teammates? Questions about trusting robots were asked via statements to which the respondents were asked to agree or disagree (Fig. 3). More than half of the respondents $(153 ; 55 \%)$ trusted robots and thought humans make more mistakes in the factory than robots do. Only 35 (13\%) respondents did not trust robots (disagree or fully disagree) and 23 respondents $(8 \%)$ thought robots make more mistakes than humans do. The ability to work with robots was considered an important future skill by 203 (73\% agree or fully agree) respondents, and $60 \%$ (168) related the knowledge-related factor of the quality of cars to robots ("Today, high-quality cars cannot be made without robots"). Most respondents (185; 66\%) considered the factory teams as only consisting of people, and $76(27 \%)$ saw robots and humans forming teams together. Two chose the option "other" and explained that the teams consist of only robots, or they explained that there are no teams and that the work is conducted in the form of projects.

The connections among knowledge, trust, and teams were analysed with cross-tabulation and $\chi^{2}$ tests (Table 3). A few statistical significances between the groups are evident. Those who consider robots to possess knowledge trust robots more often $(p=0.002)$. No differences exist between those who consider robots to be teammates and those who consider only humans to be

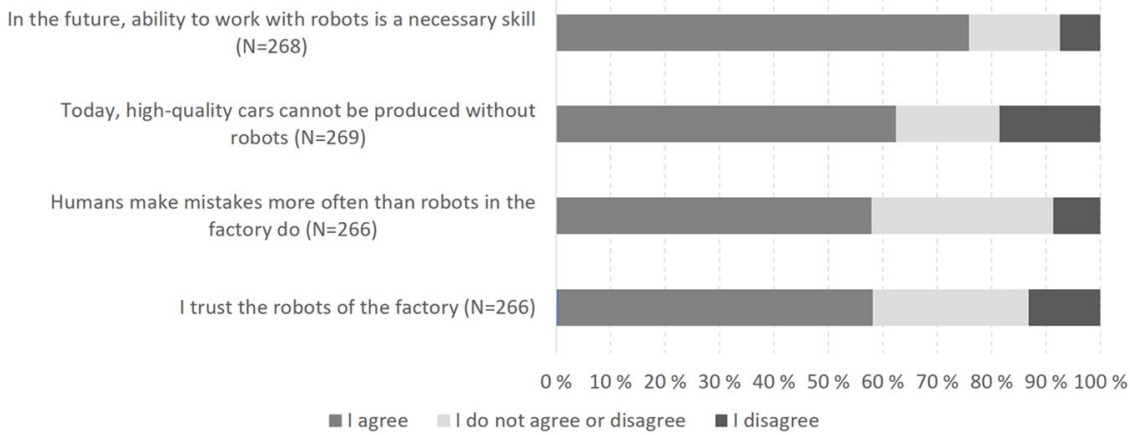

Fig. 3 Working with robots. Employees agreeing and disagreeing with statements.

Table 3 Results of the $\chi^{2}$ tests.

\section{Arguments}

I trust the robots of the Valmet Automotive (I disagree/I neither disagree nor agree/I agree)

Teams of the factory consist of.... (Humans/ Humans and robots/Other)
Can robots possess knowledge? (yes/no)

$0.002^{\mathrm{a}}$

0.070

aStatistically significant differences between groups. 

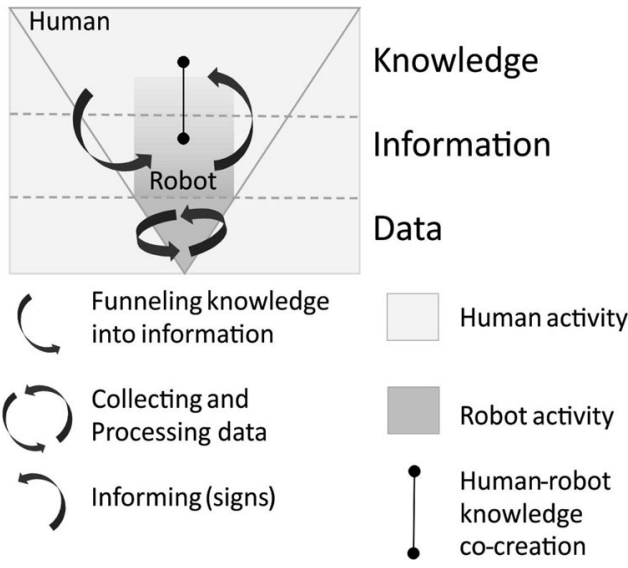

Fig. 4 The DIK(W) rethought. The DIK(W) pyramid via human-robot knowledge co-creation.

teammates. In other words, those who do not see robots as teammates may still think that they can possess knowledge.

\section{Discussion: Rethinking DIK(W) through human-robot knowledge co-creation}

The results suggest three points for developing the DIK(W) pyramid in human-robot collaboration (Fig. 4). First, the pyramid needs to recognise actors-specifically, people and robotsand their different abilities in knowledge co-creation processes. The original pyramid is based on a human-centric understanding of knowledge. However, according to the results of this survey, in a robotised automotive factory, every second employee trusts robots and considers them able to possess knowledge. For $60 \%$ of them, creating high-quality outcomes (i.e., cars) requires robots. About every third employee considers robots to be members of teams.

The "reality" concerning data, information, and knowledge for a person and a robot is different. A robot fits well into the positivist thinking behind the DIKW model, which several engineering scientists apply to develop cognitive robots (e.g., Mishra, 2018; Yao, 2020). The survey results show the employees of the automotive factory recognise robots as collecting and applying data (e.g., location and position), as well as transforming data into information; that is, robots use "were" as a key question, but without understanding "why" (Ackoff, 1989, cited in Rowley, 2007, p. 166; Frické 2009). Here, data are processed with software programmes to commit acts, such as painting a car. In Fig. 4, the robot is positioned in the $\mathrm{D}$ and I sections, although its ability to create knowledge is dependent on people. The robot can inform a person using a sign, but the person must attach meaning to the sign; for instance, the person must understand whether the quality and timing of painting is justified to reach the desired outcome (a high-quality car). A robot is designed to repeat actions in a sequential order determined by a programme. A robot is an actor that creates knowledge in the positivistic realm of the DIK(W) pyramid. However, following Fricke's (2009) critique, positivism is problematic from the human perspective because recognising tacit embodied knowledge is challenging. Emotions, intuition, experiences, previous knowledge, and context (space) all affect people's sense of the environment and interpretation of data or information (Sato and Huang, 2015, p. 615; Picca, 2020). Many robot developers tackle the challenge of tacit knowledge, for example, by developing context-aware systems (Perera et al., 2014).

The data, information, and knowledge categories are not in sequential order but rather become mixed. In Fig. 4, a person is positioned in a place that a robot cannot access-also beyond the pyramid. For example, if the robot lacks data and information, it has no overall knowledge by which to make a guess. This form takes into account Frické's (2009) important notion that not all knowledge is based on codified and explicit data.

Second, the pyramid is upside-down, but the order of the data, information, and knowledge differs from the original funnel visualisation (Fig. 1). The difference is based on the observation from the survey that "programming" is a key term for expressing the knowledge that robots can possess or justifying why robots cannot possess knowledge. When human-robot interactions are included, it becomes visible that the transformations among data, information, and knowledge go both ways (Mishra, 2018). Thus, the core question involves transforming (simplifying and funnelling) knowledge into programmes (from $\mathrm{K}$ to I) so that programmes can be transferred from people (K) to robots (I, D) in such a way that a robot can then co-create knowledge with humans by transforming and transferring from robot I and D to human $\mathrm{K}$ ? What is lost when knowledge is funnelled to programmes (I) that control the collection and application of data (Rowley, 2007)? Some engineers think that through the development of technology, all knowledge will be able to be extracted from the people and transferred to robots "as is" (Forsythe, 1993). However, this would be against the tacit and embodied understanding of knowledge that some engineers recognise and aim to use to develop machines that can engage in increasingly deep interaction with humans-and thus know with and through humans.

Third, knowledge is a dividing term. The review of existing research demonstrated some researchers consider robots able to possess knowledge (Das et al., 2007; Luo et al., 2015; Miao et al., 2018), but others think they cannot (Sanzogni et al., 2017; Sardar, 2020; Picca, 2020). This exploratory study suggests the factory employees hold similarly divided views. Half of the respondents said robots could possess knowledge, and the other half said they could not. When justifying their answers (yes or no), most respondents mentioned the role of people. Summing up the survey responses, knowledge in a human-robot collaboration stems from people programming robots to collect data and then processing data into information (an activity of the robot), which is a key part of the process (of producing new cars). The dividing factor in respondents' understanding of knowledge is the independency of the knowing actor. Those who said that robots could possess knowledge thought robots could possess knowledge together with humans. This resembles a post-human constructionist understanding of knowledge (Wenger, 1998; Hayles, 2017). Those who said robots could not possess knowledge believe robots should possess it independently for that to occur. On the one hand, the roots are in an anthropocentric and technology-assisted understanding of knowledge: It is the independent human who knows. The responses reveal the factory's robots lack central features of knowledge: the ability to learn, create something new, be creative, and apply knowledge in changing situations. On the other hand, many of the respondents expressed that robots are not "yet" developed enough, which suggests they believe robots may possess knowledge in the future despite not being human. Perhaps a novel understanding of knowledge is starting to form alongside the anthropocentric view, both in the worlds of science and practical work. In general, improving the understanding of the human-robot co-creation process of knowledge and the ways the different "realities" of people and robots come together is important (Fig. 4). For this, the presented exploratory study is an interesting start, but the subject needs empirical case studies and detailed ethnographic research. 


\section{Conclusions}

This article was aimed at rethinking the $\mathrm{DIK}(\mathrm{W})$ pyramid through human--robot co-creation and from the perspective of the employees of the most robotised factory in Finland, Valmet Automotive. The specific interest was in analysing whether the employees consider robots to possess knowledge, what kind of knowledge, or why robots cannot possess knowledge. The key contributions of the article are practical and theoretical.

From a theoretical perspective of developing the DIK(W) model, two contributions are central. First, DIK(W) is a theoretical model that lacks empirical studies. This exploratory study provides a relevant empirical starting point for revising the concepts of knowledge, information and data in the human-robot co-creation process. According to the results, robots can possess data and information. However, the question 'where' is critical for the information of robots, whereas the question of 'why' belongs to the information of humans. The results also show that knowledge is a concept that divides not only researchers but also employees who work with robots. Every second employee considers robots to possess knowledge-together with humans (Ardolino et al., 2018; Panganiban et al., 2020). They also trust robots more compared with those who do not think that robots can possess knowledge. The results suggest that the basic understanding of knowledge both for the survey respondents and the $\operatorname{DIK}(\mathrm{W})$ pyramid is anthropocentric and bound to being human. Those who consider robots to possess the knowledge to explain knowledge through a constructionist and technologyassisted understanding. The constructionist perspective emphasises that knowledge is created in interactions between humans (Wenger, 1998), but in the case of this article, it is also created between humans and robots. However, those who do not think that robots can possess knowledge to add "for now." Although robots will not become humans, they see robots as potentially possessing knowledge as technology develops. This may mean that a non-anthropocentric, novel understanding of knowledge is beginning to emerge in the robotising knowledge work.

Second, the DIK(W) pyramid is re-constructed in a way that takes criticism into account. Although the pyramid is classic and widely applied, this is the first study to acknowledge both humans and robots as actors-but with different abilities when it comes to processing data, information, and knowledge. The respondents who mentioned that robots cannot possess knowledge brought up that robots follow the programmes and lack the freedom, creativity, and ability to act independently, learn, and adjust what they have learned. These are components related to the knowledge that are less frequently discussed in the research applying the $\mathrm{DIK}(\mathrm{W})$ pyramid, but they become visible as robots are acknowledged as knowledge-creating actors. The robot exists in the positivistic realm of the original pyramid, whereas the human's realm widens the pyramid with tacit, embodied knowledge, as well as knowledge created outside of empirical and measurable data.

From the practical perspective of factories and the development of robots, this study presents interesting findings. The aim in factories and the development of robots should be to ensure effective and critical human-robot collaboration in the knowledge-based production process. The core task for engineers is to understand the different realities of humans and robots in terms of knowledge. Robots can assist humans in co-creating knowledge, but the employees need to be aware of the limitations of robots in terms of knowledge. Only humans can "know" when robots make mistakes. This supports the aim of developing transparent robots but also provides proper education for the employees to understand and programme robots. Respondents brought up programming from human's knowledge to robot's information as a key practice connecting humans and robots to co-create knowledge. Interestingly, among the respondents, it was the experts more often than the workers who justified why robots cannot possess knowledge. In sum, the revised DIK(W) pyramid offers potential for engineering cognitive and collaborative robots (Fig. 4). Focus here is on the transformations among knowledge, information, and data, and the different roles of humans and robots concerning each.

This exploratory study is based on a survey that is suitable for considering the contents that the respondents relate to knowledge, information, and data. However, further empirical, qualitative, and ethnographical research is required for understanding the practices of knowledge co-creation in human-robot collaboration. Specifically, looking at the moments in human-robot interaction where knowledge is either accepted or refused would provide important insights into how DIK(W) components are applied, neglected, and further created. Moreover, repeating this survey in various robotised factories in different parts of the world would offer valuable and comparable results across cultures.

\section{Data availability}

The datasets generated during and/or analysed during the current study are not publicly available due to (i) collaborative data collection between two institutions, and (ii) to protect the anonymity of the respondents, but are available from the corresponding author on reasonable request.

Received: 23 December 2020; Accepted: 31 August 2021; Published online: 14 September 2021

\section{References}

Ackoff R (1989) From data to wisdom. J Appl Syst Anal 16(1):3-9

Anthes E (2017) The shape of work to come. Nature 550(7676):316-319

Ardolino M, Rapaccini M, Saccani N et al. (2018) The role of digital technologies for the service transformation of industrial companies. Int J Prod Res 56(6):2116-2132

Batra S (2014) Big data analytics and its reflections on DIKW hierarchy. Rev Manag 4(1-2):5-17

Baskarada S, Koronios A (2013) Data, information, knowledge, wisdom (DIKW). Australasian J Inf Syst 18(1):5-24

Bauer A (2017) Foreword. In Wittman Kunststoffgeräte GmbH (ed): World robotics. International Federation of Robotics (IFR), Statistical Department, pp. 3-4

Bissell D, Del Casino V (2017) Whither labor geography and the rise of the robots? Soc Cult Geogr 18(3):435-442

Biswas M, Romea M, Cangelosi A et al. (2020) Are older people any different from younger people in the way they want to interact with robots? J Multimodal User Interfaces 14:61-72

Campanozzi L, Guglielmelli E, Cella E et al. (2019) Building trust in social robotics. IEEE Technol Soci Mag 38:45-54

Csikszentmihalyi M (1997) Creativity: Flow and the psychology of discovery and invention. Harper Perennial

Coeckelbergh M (2012) Can we trust robots? Ethics Inf Technol 14:53-60

Collins H (2010) Tacit and explicit knowledge. University of Chicago Press, Chicago

Cruz E, Bauer Z, Rangel J, Cazorla M, Gomez-Donoso F (2019) Semantic localization of a robot in a real home. Adv Intell Syst Comput 855:3-15

Das S, Hu Y, Lee C et al. (2007) Mobility-aware ad hoc routing protocols for networking mobile robot teams. J Comm Netw 9:296-311

Elprama B, El Makrini I, Jacobs A (2016) Acceptance of collaborative robots by factory workers. In: 25th IEEE International Symposium on Robot and Human Interactive Communication (RO-MAN 2016), 26-31 August. IEEE, New York

Epstein S (2010) Demystifying intuition: what it is, what it does, and how it does it. Psychol Inquiry 21(4):295-312

Eyvindson K, Kangas A et al. (2015) Likert versus Q-approaches in survey methodologies. Qual Quant 49:509-522

Finland's Age of Artificial Intelligence (2017) Steering group of the artificial intelligence programme. 18 December 2017

Forsythe DE (1993) Engineering knowledge. Soc Stud Sci 23(3):445-477 
Frické M (2009) The knowledge pyramid. J Inf Sci 35(2):131-142

Frické M (2019) The knowledge pyramid. Knowl Organ 46(1):0943-7444

Green C (2012) Nursing intuition. Nurs Philos 13(2):98-111

Guznov S, Lyons J, Pfahler M et al. (2020) Robot transparency and team orientation effects on human-robot teaming. Int J Hum-Comput Interact. https:// doi.org/10.1080/10447318.2019.1676519

Hautala J, Höyssä M (2017) Knowledge rationales in human geography. Nor Geogr Tidsskr 71(5):1-19

Hayles K (2017) Unthought. University of Chicago Press, Chicago

Heino H, Hautala J (2020) Mobile futures knowledge. Geoforum 118:83-92

Hentout A, Aouache M, Maoudj A, Akli I (2019) Human-robot interaction in industrial collaborative robotics. Adv Robot 33(15-16):764-799

Hippertt MP, Junior ML, Szejka AL et al. (2019) Towards safety level definition based on the HRN approach for industrial robots in collaborative activities. Procedia Manuf 38:1481-1490

Hogarth R (2001) Educating intuition. University of Chicago Press, Chicago

Hsieh H, Shannon SE (2005) Three approaches to qualitative content analysis. Qual Health Res 15(9):1277-1288

International Federation of Robotics (IFR) (2017). World robotics 2017. International Federation of Robotics (IFR)

Jifa G, Lingling Z (2014) Data, DIKW, big data and data science. Procedia Comput Sci 31:814-821

Jerman A, Pejić Bach M, Aleksić A (2020) Transformation towards smart factory system. Syst Res Behav Sci 37(2):388-402

Kahan T, Bukchin Y et al. (2009) Backup strategy for robots' failures in an automotive assembly system. Int J Prod Econ 120(2):315-326

Lake B, Ullman T, Tenenbaum J et al. (2017) Building machines that learn and think like people. Behav Brain Sci 40:1-72

Larson L, DeChurch LA (2020) Leading teams in the digital age. Leadersh Q 31:101377

Lee J, Moray N (1992) Trust, control strategies and allocation of function in human-machine systems. Ergonomics 35(10):1243-1270

Lobov A (2018) Smart manufacturing systems: climbing the DIKW pyramid. In Nogueiras-Melendez A (ed): IECON 2018-44th annual conference of the IEEE Industrial Electronics Society. IEEE, pp. 4730-4735

Luo R, Wu Y, Lin P (2015) Multimodal information fusion for human-robot interaction. In: SACI 10th jubilee IEEE international symposium on applied computational intelligence and informatics, Anonymous, 21-23 May, Timisoara. IEEE, pp. 535-540

Matthews G, Lin J, Panganiban A et al. (2020) Individual differences in trust in autonomous robots. IEEE Trans Hum Mach Syst 50:234-244

Matthias B, Kock S, Jerregard H et al. (2011) Safety of collaborative industrial robots. In Okamura A (ed): Proceeding of the IEEE International Symposium on Assembly and Manufacturing (ISAM). pp. 1-6

MCBride K, Steffens D, Duncan K et al. (2019) Knowledge and attitudes of theatre staff prior to the implementation of robotic-assisted surgery in the public sector. PLoS ONE 14(3):e0213840

Miao Z, Liu Y, Wang Y et al. (2018) Distributed estimation and control for leaderfollowing formations of nonholonomic mobile robots. IEEE Trans Autom Sci Eng 15:1946-1954

Milliez G, Lallement R et al. (2016) Using human knowledge awareness to adapt collaborative plan generation, explanation and monitoring. In Belpaeme $\mathrm{T}$, Young J (eds): Proceedings of the 11th ACM/IEEE international conference on human-robot interaction. IEEE Press, pp. 43-50

Mishra AK (2018) A DIKW architecture for cognitive engineering. Procedia Comput Sci 123:285-289

Nonaka I, Takeuchi H (1995) The knowledge-creating company. Oxford University Press, Oxford

Panganiban AR, Matthews G, Long MD (2020) Transparency in autonomous teammates. J Cogn Eng Decis Mak. https://doi.org/10.1177/1555343419881563

Pereira F (2007) Creativity and artificial intelligence: a conceptual blending approach. Walter de Gruyter

Perera C, Zaslavsky A, Christen p et al. (2014) Context aware computing for the Internet of Things: a survey. IEEE Commun Surv Tutorials 16:414-454

Picca D (2020) From intelligent to wise machines. Informatik Spektrum 43:28-39

Pohlt C, Haubner F, Lang J et al. (2018) Effects on user experience during human-robot collaboration in industrial scenarios. In O'Conner L (ed): Conference proceedings of the IEEE international conference on System, Man and Cybernetics (SMC). pp. 837-842

Polanyi M (1983) The tacit dimension, 2nd edn. Doubleday \& Company, New York

Pynadath D, Wang N, Kamireddy S (2019) A Markovian method for predicting trust behavior in human-agent interaction. In: 7th International conference on human-agent interaction, October. Association for Computing Machinery, Kyoto, pp.171-178

Rantanen T, Lehto P, Vuorinen P et al. (2018) The adoption of care robots in home care. J Clin Nurs 27(9-10):1846-1859

Ray C, Mondada F (2008) What do people expect from robots? In: IEEE/RSJ international conference on intelligent robots and systems, 22-26 September IEEE, Nice, pp. 3816-3821

Rowley J (2007) The wisdom hierarchy. J Inf Sci 33(2):163-180

Runco M, Jaeger G (2012) The standard definition of creativity. Creat Res J 24(1):92-96

Rusu R, Holzbach A, Beetz M, Bradski G (2009) Detecting and segmenting objects for mobile manipulation. In: IEEE 12th International Conference on Computer Vision workshops, ICCV workshops 2009 5457718, Kyoto, Japan, 27 September-4 October. IEEE, Kyoto, pp. 47-54

Sanzogni L, Guzman G, Busch P (2017) Artificial intelligence and knowledge management. Prometheus 35(1):37-56

Sardar Z (2020) The smog of ignorance. Futures 120:102554

Sato A, Huang R (2015) A generic formulated KID model for pragmatic processing of data, information, and knowledge. In Ma J (ed): IEEE 12th international conference on Ubiquitous Intelligence and Computing and 2015 IEEE 12th international conference on Autonomic and Trusted Computing and 2015 IEEE 15th International Conference on Scalable Computing and Communications and Its Associated Workshops (UIC-ATC-ScalCom). pp. 609-616

Schuman H, Presser S (1996) Questions and answers in attitude surveys. Sage Publications, Thousand Oaks

Slutskaya N (2006) Creativity and repetition. Creativity Innov Manag 15(2):150-156

Shalley C, Gilson L (2017) Creativity and the management of technology: balancing creativity and standardization. Prod Oper Manag 26(4):605-615

Taddeo M (2010) Trust in technology. Knowl Technol Policy 23(3-4):283-286

Valmet Automotive (2020) Valmet automotive. https://www.valmetautomotive.com/. Accessed 5 May 2020

Wenger E (1998) Communities of practice. Cambridge University Press, Cambridge

Yao Y (2020) Tri-level thinking. Int J Mach Learn Cybern 11:947-959

\section{Acknowledgements}

I thank Olli Nevalainen for collecting the survey. The research was funded by the Academy of Finland, project nr. 319872 Second Machine Age Knowledge Co-Creation Processes in Space and Time.

\section{Competing interests}

The author declares no competing interests.

\section{Additional information}

Correspondence and requests for materials should be addressed to Johanna Hautala.

Reprints and permission information is available at http://www.nature.com/reprints

Publisher's note Springer Nature remains neutral with regard to jurisdictional claims in published maps and institutional affiliations.

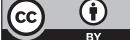

Open Access This article is licensed under a Creative Commons Attribution 4.0 International License, which permits use, sharing, adaptation, distribution and reproduction in any medium or format, as long as you give appropriate credit to the original author(s) and the source, provide a link to the Creative Commons license, and indicate if changes were made. The images or other third party material in this article are included in the article's Creative Commons license, unless indicated otherwise in a credit line to the material. If material is not included in the article's Creative Commons license and your intended use is not permitted by statutory regulation or exceeds the permitted use, you will need to obtain permission directly from the copyright holder. To view a copy of this license, visit http://creativecommons.org/ licenses/by/4.0/

(C) The Author(s) 2021 